\title{
Academic Norms Education Based on MOOC: Learning and Assessment
}

\author{
Changyong Yang ${ }^{1, \mathrm{a}}$, Jing Zhou ${ }^{2, \mathrm{~b}}$, Wei He ${ }^{3, \mathrm{c}}$ and Kun Zheng, ${ }^{3, \mathrm{~d}, *}$ \\ ${ }^{1}$ College of Humanities, Beijing University of Technology, City, Beijing, China \\ ${ }^{2}$ College of Continuing Education, Beijing University of Technology, Beijing, China \\ ${ }^{3}$ Faculty of Information Technology, Beijing University of Technology, Beijing, China \\ ayangchangyong58@bjut.edu.cn, ${ }^{b}$ zhoujing_23@bjut.edu.cn, ${ }^{c}$ hewei@bjut.edu.cn, ${ }^{d}$ zhengkun@bjut.edu.cn \\ *Corresponding author
}

\begin{abstract}
At present, there is a general lack of systematic education on academic norms for college teachers, especially young teachers. Based on this, this paper has analyzed and designed the knowledge system of academic normative education and the compilation of academic normative education. The system of academic normative education was established and the self-learning and evaluation of academic norms was realized. It can provide support and reference for improving young teachers' academic literacy.
\end{abstract}

Keywords: $M O O C$, academic norms education, learning and assessment

\section{基于慕课的学术规范教育: 学习与评测

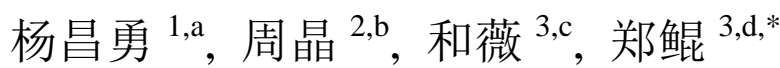

\author{
1 人文学院，北京工业大学，北京，中国 \\ 2 继续教育学院, 北京工业大学, 北京, 中国 \\ 3 信息学部, 北京工业大学, 北京, 中国 \\ ayangchangyong58@bjut.edu.cn, ${ }^{b}$ zhoujing_23@bjut.edu.cn, ${ }^{c}$ hewei@bjut.edu.cn, ${ }^{\text {h } h h e n g k u n @ b j u t . e d u . c n}$ \\ *通讯作者
}

\section{摘要}

目前高校普遍缺乏针对高校教师尤其是青年教师的系统性的学术规范教育。本文分析并设计了学术规 范教育慕课的知识体系以及学术规范教育慕课的编制, 建立了基于学术规范教育的慕课系统, 并实现 学术规范的自我学习与评测。可为提高高校教师尤其是青年教师的学术素养提供支持和参考。

关键词: 慕课, 学术规范教育, 学习与评测

\section{1. 引言}

我国学术界存在着较为普遍而严重的学术失范, 大多数学 者没有经过系统而严格的学术规范训练, 高等学校普遍存 在着学术规范教育的缺乏或低效问题, 并且这一情况形成 了恶性循环。

\section{2. 国内外相关研究}

根据我们对学术史资料的掌握, 学术规范教育的慕课 (MOOC) 系统在国内外极为少见, 可作为本课题研究基 础的学术史研究的主要有如下几个方面:

(1) 慕课 (MOOC)。MOOC, 英文全称是 Massive Open Online Course, 中文全称为大规模在线开放课程。2008 年兴起于加拿大, 很快在美国流行, 2012 年形成全球教 育界的“数字海啸”, 网络学分也获得了美国大学的承认, 2013 年起我国一批名校也参与进来了。MOOC 的教育理 念、教学实践、课程编制及网络技术为本课题的研究提供
了基础。

(2) 涉及学术规范教育的慕课。目前的在线课程如: Crafting and Effective Writer、Writing in the Sciences 、 College Writing 2.1x: Principles of Written English 、 Developing Your Research Project 、 Reasoning、Data Analysis, \& Writing Final Project 等, 它们在一定程度上涉 及到学术规范中的写作规范, 为我们的学术规范教育的慕 课系统建设提供了借鉴。

（3）学术规范建设。国内外的学术规范建设, 为本课题 学术规范教育提供了课程知识。国外的主要有芝加哥手册、 APA 手册、MLA 手册、纽约时报手册和韦伯标准等; 国 内的主要有: 国家标准 1987 年《文后参考文献著录规则》、 《科学技术报告、学位论文和学术论文的编写格式》, 光 盘版标准 1998 年《中国学术期刊(光盘版)检索与评价数 据规范》等。

(4) 学术规范与学术规范教育研究。学术规范和学术规 范教育问题, 是典型的社会学问题。早在 1942 年, 默顿 就把科学规范作为一种社会制度进行分析[1], 并揭示了 这样一个事实: 学术规范建设和学术规范教育交织在学术 
问题已严重危及到了国家的安全。提高学术规范教育的有 效性，是时代赋予我国教育的历史使命。[5-9]

\section{3. 研究设计}

研究对象包括学术规范教育慕课的知识体系、学术规范教 育慕课的编制和学术规范教育慕课系统的应用三个方面。 首先要有效地进行学术规范教育, 必须有合适的教育 “内 容”。研究探讨如何根据本科生和研究生学术成长对学术 规范的需要来选择并组织学术规范教育的系统知识。其次 采取游戏任务式设计, 将学习与实时测评相结合, 使学习 者在学习的同时能及时得到反馈信息, 得到鼓励, 利于巩 固。然后, 争取成为大学的一门课程, 进而研究相关的教 学问题。

总体框架由两大板块组成, 如图 1 所示, 一是慕课系统的 建构, 二是慕课系统的应用。慕课系统建构研究内容的基 本框架是: A. 慕课的教育理论、技术; B. 学术规范的知识 进入课程; C. 慕课编制符合学生成长规律; D. 以学术为业 者应该具备的学术素养体系, 等等。慕课应用研究内容的 基本框架是: A. 学校教育与学术规范教育的基础关系; B. 学术规范课程设置; C.学术规范的教学, 等等。 又一代的高级知识分子、以学术为业者却缺乏基本的学 规范素养, 并形成恶性循环。在知识经济时代, 这一教育

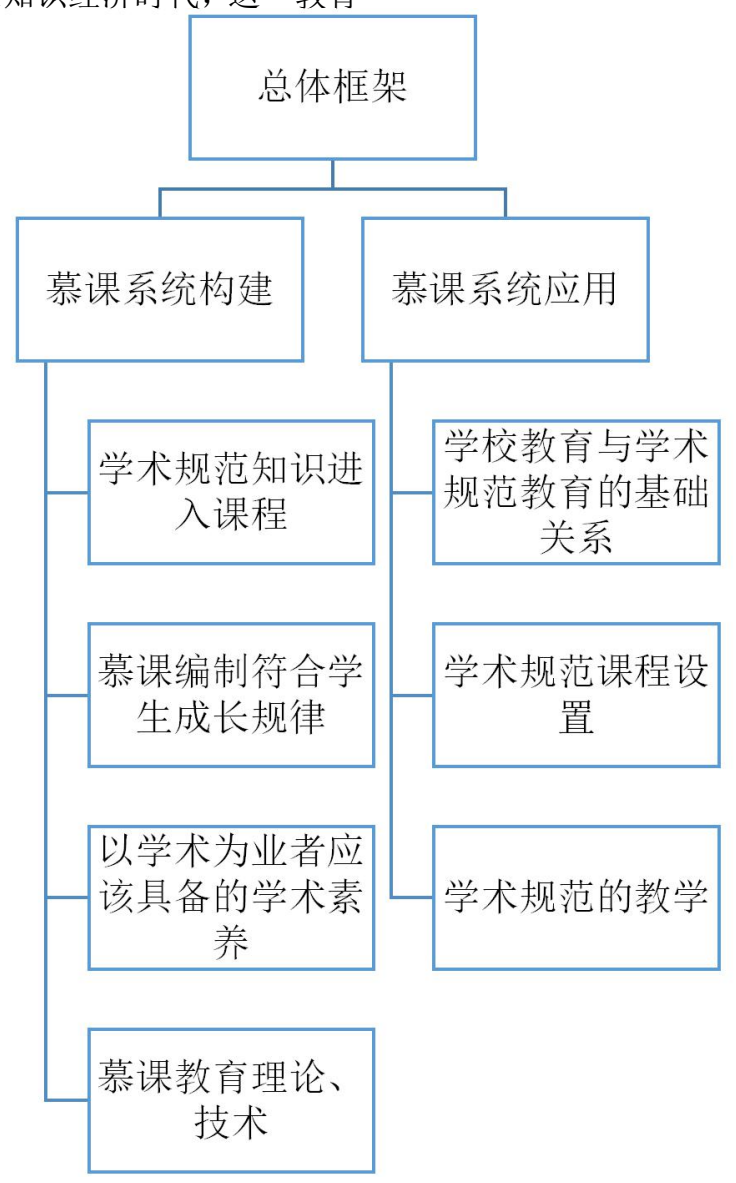

图 1 总体框架

建构学术规范教育的慕课系统, 使其成为一个有相当学术 价值的实用工具, 其难点不是慕课的编制技术, 也不是使 用本慕课的网络平台, 其研究难点一是本慕课教育知识的
选择, 因为我国学术规范、规则体系相当混乱, 相关的国 家标准、学会规范和光盘版规范相互矛盾; 二是本慕课的 官方应用, 它能否成为大学的一门有学分的课程。 


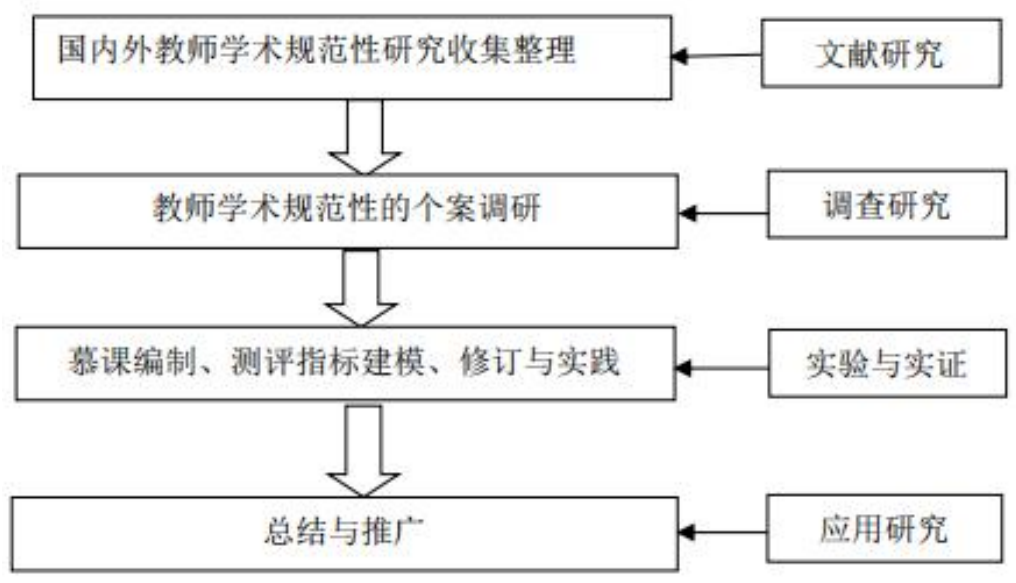

图 2 研究路线及方法

遵循“现状调查一理论研究一技术研究一慕课编制一应用 研究一总结改进” 的总体思路展开研究, 如图 2 所示。首 先, 选取国内几所大学, 调查其学术规范教育的现状, 特 别关注其成效性及存在的问题; 其次, 根据调查现状, 借 用社会学、教育学、管理学和计算机科学等相关理论进行 阐释、建构学术规范教育的慕课系统。本课题的应用研究 将从本学院开始, 争取本校和更多的学校把它作为有学分
的课程。在研究、应用中改进，在改进基础上再研究、应 用。

配合慕课学习的规范学习与测评系统软件分为管理端与 学习用户。用户进行在线学习与测评考试的各功能模块主 要有登录模块、考前学习模块、考试模块和考试评判模块。 如图 3 所示。

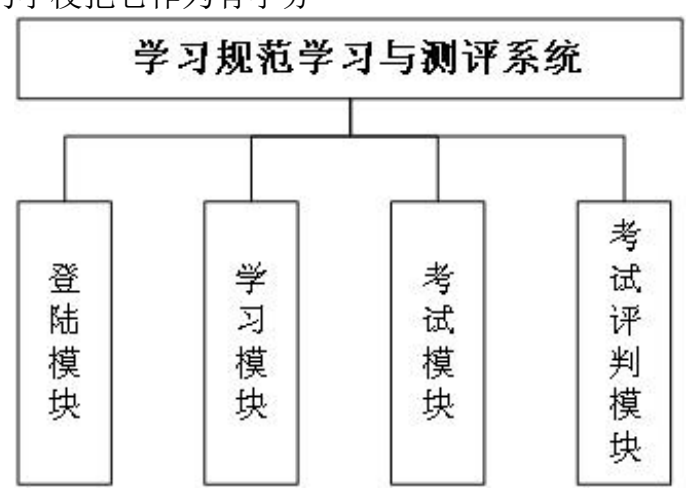

图 3 系统模块

登陆模块包括学生登录和前台数据的初始化。测评教师可 以在前台用自己的帐号和密码登陆, 并一次性把测评教师 相关信息发送到前台页面, 方便登陆系统进行在线测试。 考前学习模块可以为测评教师在正式测试 (考试) 之前提
供在线学习功能, 学习完毕进行测试 (考试)。如图 4 所示, 其中为了醒目, 学习资料中的关键文字信息设计使 用蓝色显示。 
图 4 考前学习模块界面

用户 (测评教师) 通过考试模块进行在线测评。考试评判 模块根据测评教师答题情况实时给出答题结果。如图 5 所示。单项选择部分未完成无法进入下一步。答题出错后
系统会红色高亮显示题干, 同时显示试题解释以提高用户 体验。

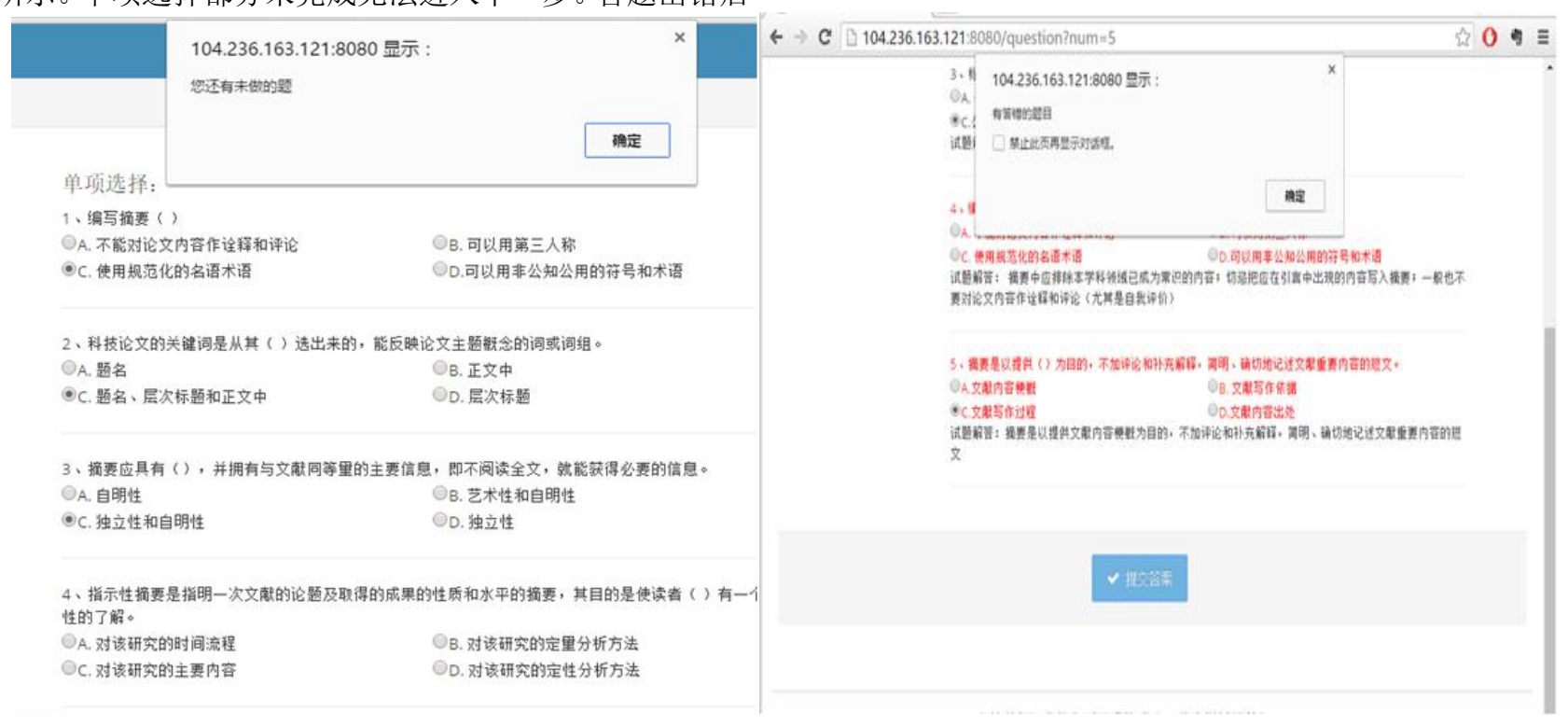

图 5 考试模块界面

\section{4. 总结}

研究成果建立在跨学科的团队合作基础上, 团队包括了教 育研究团队和信息化研究团队。建立的学术规范教育的慕 课可以作为我国大学的选修课程和必修课, 学习规范学习 系统可以作为学者和学术管理者的自我教育工具。并以学
术教育教育幕课系统的应用而提高学者和学术新人的学 术素养, 提高学术规范教育的有效性。

\section{致谢}

本文为教育部人文社会科学研究规划基金一般项目《高等 学校青年教师学术规范继续教育机制的理论与实验研究》 
(编号：15YJA880088)的阶段性成果之一。

\section{参考文献}

[1] 罗伯特・金・默顿.科学社会学[M].鲁旭东等译.北京:商 务印书馆, 2003.

[2] 保罗・奥利弗.学术道德学生读本[M].金顶兵译.北京: 北京大学出版社,2007.

[3] 唐纳德・肯尼迪.学术责任[M].阎风桥等译.北京:新华 出版社, 2002.

[4] 查尔斯・李普森.诚实做学问 [M].郜元宝等译.上海:华 东师范大学出版社, 2006.

[5] 邓正来.中国学术规范化讨论文选[M].北京:中国政法 大学出版社, 2010.

[6] 顾海良. 学术规范与学术道德:他律与自律[J].社会科学 论坛, 2005(1):11-15.

[7] 曹树基. 学术不端行为: 概念及惩治 [J].社会科学论坛, 2005(3):36-40.

[8] 阎光才.我国学术职业环境的现状与问题分析[J].高等 教育研究, 2011(11):1-9.

[9] 陈学飞.谈学术规范及其必要性 [J].中国高等教育, 2003(11):23-23. 